\title{
Cambio climático y construcción de alternativas: hacia una agricultura sustentable para enfriar el planeta
}

\author{
Jaime Morales Hernández
}

La humanidad se enfrenta a una crisis compleja y multidimensional. El cambio climático es una de las consecuencias más evidentes de un proyecto civilizatorio basado en la industrialización de la naturaleza y el uso intensivo de recursos naturales. La agricultura industrial se extiende como el proceso hegemónico en la producción de alimentos y constituye una amenaza para la vida rural, los agricultores y los consumidores, además de que representa una de las causas del cambio climático. Ante ello, el presente texto pretende dar cuenta de los avances en la construcción de alternativas agrícolas sustentables en América Latina.

CRISIS PLANETARIA, CAMBIO CLIMÁTICO Y ALIMENTOS

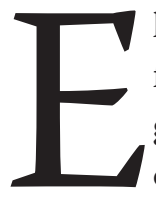
l cambio climático forma parte de una profunda crisis civilizatoria. De acuerdo con Edgar Morin, ${ }^{1}$ estamos ante una combinación de crisis entretejidas e indisociables que incluyen las dimensiones económica, ecológica, demográfica, urbana y rural. En conjunto se trata de una crisis planetaria que cuestiona a fondo los dos mitos principales del Occidente moderno: la conquista de la naturaleza-objeto y el falso infinito hacia donde se lanzan el crecimiento, el desarrollo y el progreso.

La crisis rural está inmersa en la crisis civilizatoria y muestra el fracaso de la agricultura industrializada y los sistemas agroalimentarios impuestos a nivel global por las políticas neoliberales. Las evidencias son múltiples: a) incapacidad para reducir el hambre a pesar de los altos niveles de producción existentes; $b$ ) incremento de la pobreza y la marginación de los habitantes rurales que se 
ven obligados a emigrar del campo buscando mejores niveles de vida; $c$ ) continuo deterioro de los recursos naturales, incluso con respecto al cambio climático, yd) condiciones de calidad y confiabilidad de los alimentos que cada vez entrañan más riesgos para los consumidores.

La alteración de los patrones climáticos afectará a la producción agropecuaria y tendrá un impacto directo sobre la producción de alimentos. La alimentación, el nivel más básico de las necesidades humanas, se está viendo gravemente influenciada por los efectos del cambio climático, aumentando con ello el número de personas en riesgo de hambruna. De esta forma, el cambio climático y la seguridad alimentaria están indisolublemente ligados. La Organización de las Naciones Unidas señala que además de los 1200 millones de hambrientos actuales en el mundo, para 2080 otros 600 millones podrían estar en riesgo de padecer hambre como consecuencia directa del cambio climático. ${ }^{2}$ A nivel global, los impactos del cambio climático serán más intensos en aquellos seres humanos quienes menos tienen la culpa, especialmente para quienes basan la subsistencia en la utilización de recursos naturales. Entre ellos se encuentran los habitantes del medio rural y las orillas de mares, ríos y lagos, especialmente en el llamado Sur global, en el cual campesinos, jornaleros, pequeños pescadores, mujeres e indígenas enfrentan una compleja crisis rural, caracterizada por pobreza, hambre, deterioro ambiental y migración forzada.

La agricultura es una de las actividades humanas que por su estrecha relación con la naturaleza y con el clima se verá fuertemente impactada por el cambio climático. La cantidad y distribución de las lluvias, la variación entre altas y bajas temperaturas, las inundaciones, las sequías, los incendios, la erosión del suelo y la pérdida de la agrodiversidad son sólo algunos de los impactos previstos que tendrán un efecto directo en la producción de alimentos y, por tanto, en la alimentación de la humanidad.

Las consecuencias pueden ser muy profundas para los agricultores de subsistencia ubicados en ecosistemas frágiles, donde se esperan cambios en la productividad. En estas circunstancias, la disminución de tan sólo una tonelada en el rendimiento puede llevar a grandes desequilibrios en la vida rural. La mayoría de los modelos de cambio climático predice que los daños serán sufridos en forma desproporcionada por los pequeños agricultores del Sur global, particularmente por agricultores que dependen de regímenes de lluvia impredecibles. ${ }^{3}$

\section{AgRICULTURA INDUSTRIAL Y} CAMBIO CLIMÁTICO

A pesar de las múltiples evidencias de la crisis rural a nivel planetario, la globalización neoliberal se encamina a intensificar los procesos de industrialización de la agricultura con el único criterio de aumentar la rentabilidad, excluyendo cualquier visión que considere la multifuncionalidad y los aportes sociales, culturales o ecológicos de las actividades agropecuarias. La agricultura industrial lleva en su esencia la modificación intensiva de los ecosistemas; su estilo tecnológico se basa en el monocultivo, las semillas híbridas y transgénicas, y la utilización de insumos de origen industrial, tales como fertilizantes químicos, plaguicidas y combustibles fósiles.

La agricultura industrial se extiende por el planeta a través de diferentes procesos: la sustitución de abonos orgánicos por fertilizantes químicos; la utilización de maquinaria cada vez más grande, costosa y pesada; la transformación de la ganadería en granjas intensivas y dependientes; la pérdida de la agrodiversidad; la creciente especialización productiva regional, y el incremento progresivo en el comercio global de alimentos. ${ }^{4}$

Con la extensión de la agricultura industrial se intensifican las aportaciones de esta actividad al cambio climático. Se calcula que genera $14 \%$ de las emisiones directas de gases con efecto invernadero (GEI). Por otra parte, otro $18 \%$ de las emisiones de GEI corresponde a cambios en el uso de la tierra a nivel global y más de la mitad de éstas son causadas por la agricultura industrial, principal causa de la deforestación, apertura de nuevas tierras de cultivo y degradación de los suelos. ${ }^{5}$ También hay que agregar las emisiones indirectas, como la energía gastada en la fabricación de agroquímicos, la producción y utilización de maquinaria agrícola, el transporte de insumos y cosechas, así como las emisiones generadas en la elaboración, envasado y transporte de alimentos. Con todo, queda claro que la agricultura industrial es una de las principales culpables del cambio climático.

\section{Agricultura sustentable Y CONSTRUCCIÓN DE ALTERNATIVAS}

Ante la crisis que recorre los espacios rurales en el mundo, campesinos e indígenas llevan a cabo diversas estrategias para construir alternativas que conserven la cul- 
tura, los recursos naturales y los medios de vida. Entre estas estrategias juega un papel relevante la búsqueda de formas más sustentables de practicar la agricultura. Los protagonistas de los movimientos rurales buscan, además, establecer articulaciones con diversos tipos de organizaciones sociales: ecologistas, consumidores, neorurales y no gubernamentales, con la perspectiva de entretejer acuerdos comunes con los habitantes de las ciudades, que son una contraparte fundamental de la agricultura sustentable, ya que constituyen compañeros fundamentales en el caminar colectivo hacia la construcción de otro tipo de relaciones entre la ciudad y el campo, caracterizadas por una alimentación accesible, sana y de alta calidad. La agricultura sustentable atiende

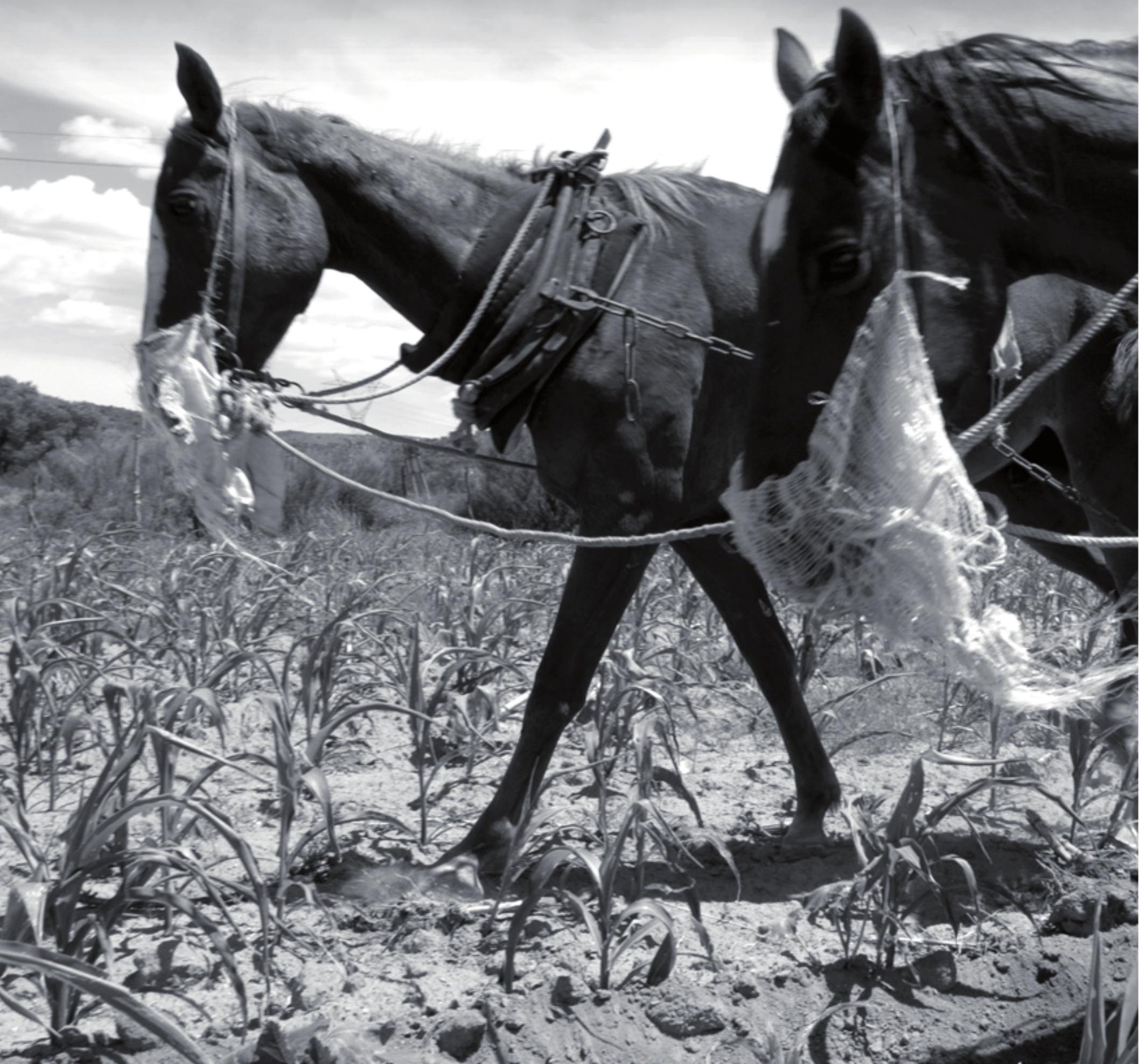


manejar la tierra de tal manera que el suelo queda cubierto permanentemente a través de la reducción del laboreo, la diversificación y la rotación de cultivos y la agroforestería; b) utilizar leguminosas para ayudar a mantener la fertilidad del suelo; c) fertilizar con estiércoles y residuos orgánicos, incluyendo no sólo la elaboración de abonos, compostas y biogás, sino también el reciclaje de residuos urbanos; $d$ ) integrar la agricultura con la ganadería, y $e$ ) alimentar el ganado con praderas y piensos locales, y evitar la ganadería que implica estabulación intensiva. La agricultura sustentable también implica cambios en la conducta de los consumidores para consumir más alimentos locales y regionales y más vegetales en la dieta.

Estos patrones se reflejan en el continuo crecimiento de la superficie manejada con una visión de agricultura sustentable, que en 2008 incluía un total de 35 millones de hectáreas en 154 países del mundo, manejadas por alrededor de 1.4 millones de agricultores. El primer lugar lo ocupa Oceanía con 12 millones de hectáreas; después se ubican Europa y Latinoamérica con alrededor de ocho millones de hectáreas. Cabe señalar que la región donde tuvo mayor crecimiento la agricultura sustentable durante 2007 fue Latinoamérica, con un incremento de $26 \%$, donde buena parte de los agricultores son pequeños y medianos. ${ }^{8}$

\section{EXPERIENCIAS en AmÉrica Latina}

En la región, la agricultura sustentable nace como una estrategia orientada a enfrentar la crisis rural a partir de tres objetivos: autosuficiencia alimentaria familiar, cuidado de recursos naturales y reducción de costos de producción. En América Latina los proyectos iniciales fueron realizados por grupos de campesinos e indígenas, acompañados generalmente por organizaciones comunitarias y no gubernamentales (ONG). ${ }^{9} \mathrm{Al}$ paso del tiempo, y con la participación de grupos de consumidores, ecologistas, universitarios y - en algunos casos- agentes de gobiernos locales, la agricultura alternativa fue creciendo constantemente, de tal manera que $27 \%$ de la superficie que corresponde a este modelo a nivel mundial se ubica en Latinoamérica.

Esta forma de agricultura ha tenido un impacto positivo en los rendimientos. De acuerdo con Altieri y Nicholls, ${ }^{10}$ para los miles de productores rurales en
América Latina que -en asociación con ONG y otras organizaciones - manejan sistemas agroecológicos, los aumentos de 50 a 100\% en la producción son bastante comunes. En estos casos, los rendimientos de cultivos que constituyen el sustento de los pobres - arroz, frijol, maíz, yuca, papa, cebada - se han multiplicado gracias al trabajo y conocimiento local y a la intensificación de mano de obra y el aprovechamiento de sinergias.

El avance de la agricultura sustentable en la región ha significado también el manejo equilibrado de los recursos naturales, la conservación de semillas nativas, el mejoramiento de la agrodiversidad y la disminución de impactos ambientales negativos. ${ }^{11}$ Además, ante las catástrofes ambientales en Latinoamérica, la agricultura sustentable ha demostrado mayor capacidad de resistencia que la agricultura convencional. Después del huracán Mitch en Centroamérica, por ejemplo, las parcelas con prácticas de agricultura sustentable mostraron menos problemas de erosión y permitieron en un periodo corto reanudar las actividades productivas. ${ }^{12}$

Las experiencias en la región muestran la relevancia de la agroecología como un enfoque científico destinado a apoyar la transición desde los actuales estilos de desarrollo rural hacia modos más sustentables. ${ }^{13}$ Para Altieri y Toledo, ${ }^{14}$ la agroecología tiene un gran potencial para promover cambios sociales y agrarios trascendentes, que pueden traer beneficios económicos, sociales, ambientales y políticos a los pequeños productores, a las comunidades rurales y a los consumidores en general. Estos cambios abren nuevos derroteros políticos para las sociedades agrarias de la región y conforman una alternativa totalmente opuesta a las políticas neoliberales basadas en la agroindustria y las agroexportaciones. En Latinoamérica destacan como polos de innovación en agriculturas sustentables Brasil, la región andina, México, Centroamérica y Cuba. La experiencia de este último país es reveladora del potencial de la agroecología bajo un modelo socialista; los avances más impresionantes se realizaron desde 2000, cuando la agroecología empezó a difundirse en el campo a través de los canales "campesino a campesino», y también fue adoptada en los centros urbanos, huertos, azoteas y traspatios. El resultado fue un aumento dramático de la producción de verduras, leguminosos, tubérculos y otros cultivos, rebasando con creces los niveles de producción antes de la crisis, con sólo una fracción de los agroquímicos utilizados en los años ochenta. ${ }^{15}$ 


\section{REFLEXIONES FINALES}

La agricultura sustentable aparece como una alternativa a la agricultura industrial. Continúa creciendo en el mundo con notables aportaciones en el combate al cambio climático. En Latinoamérica esta forma de agricultura es realizada especialmente por agricultores familiares, campesinos e indígenas. Los movimientos sociales hacia la sustentabilidad han demostrado la importancia de la articulación de los habitantes urbanos y los rurales en la movilización y presión sobre los gobiernos y los organismos internacionales, para el diseño y puesta en práctica de políticas públicas orientadas a fortalecer la agricultura sustentable y multifuncional como una manera de enfriar el planeta y de avanzar hacia sociedades más justas y ecológicamente racionales.

\section{Referencias}

1 Edgar Morin (2011), La vía para el futuro de la humanidad, Barcelona, Editorial Paidós.

2 Olivier de Schutter (2010), La agroecología y el derecho a la alimentación. Informe del Relator Especial sobre el derecho a la alimentación al Consejo de Derechos Humanos de la Asamblea de la ONU, documento A/HRC/16/49, Nueva York, Organización de las Naciones Unidas.

3 Miguel Altieri y Clara Nicholls (2009), «Cambio climático y agricultura campesina: impactos y respuestas adaptativas», LEISA, Revista de Agroecología, volumen 24, número 4, pp. 5-8.

4 Ecologistas en Acción (2011), Agroecología para Enfriar el Planeta, Madrid, Cuadernos 19.

5 IPCC (Panel Intergubernamental sobre el Cambio Climático) (2007), Cambio climático 2007: informe de síntesis, Ginebra, OMM, PNUMA.

6 Stephen Gliessman (2007), Agroecology: The Ecology of Sustainable Food Systems, Boca Raton, Florida, CRC Press.

7 Johannes Kotschi y Karl Muller Samann (2004), The Role of Organic Agriculture in Mitigating Climate Change A Scoping Study, Bonn, IFOAM.

8 Helga Willer y Lukas Kilcher (editores) (2010), The World of Organic Agriculture. Statistics and Emerging Trends, Bonn, IFOAM.

9 Jaime Morales Hernández (2011), La agroecología en la construcción de alternativas hacia la sustentabilidad rural, México, ITESO, Siglo XXI.
10 Miguel Altieri y Clara Nicholls (2000), Agroecología: teoría y práctica para una agricultura sustentable, México, PNUMA.

11 Gloria Guzmán y Jaime Morales Hernández (2011), «Agroecología y Agricultura Ecológica. Aportes y sinergias para incrementar la sustentabilidad agraria», Revista Agroecología, volumen 6, pp. 55-62.

12 Eric Holt-Giménez (2002), «Measuring farmers agroecological resistance after hurricane Mitch in Nicaragua: a case study in participatory, sustainable land management impact monitoring», Agriculture, Ecosystems and Environment, volumen 93, pp. 87-105.

13 Francisco Caporal y José Antonio Costabeber (2002), «Analise multidimensional da sustentabilidade: uma proposta metodologica a partir da Agroecología», Revista Agroecología e desenvolvimento rural sustentavél, volumen 3, número 3, Ediciones Emater, Ascar, Brasil.

14 Miguel Altieri y Toledo Víctor (2011), «The agroecological revolution of Latin America: rescuing nature, securing food sovereignty and empowering peasants», Journal of Peasant Studies, volumen 38, número 3, pp. 587-612

15 Peter Rosset, Braulio Machín Sosa, Adilén María Roque Jaime y Dana Rocío Ávila Lozano (2011), «The Campesinoto-Campesino agroecology movement of ANAP in Cuba: social process methodology in the construction of sustainable peasant agriculture and food sovereignty», Journal of Peasant Studies, volumen 38, número 1, pp. 161-191. 